UhしUU3Uし ఒもLLh

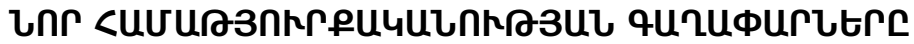

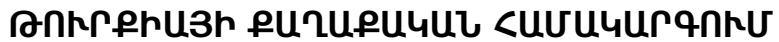

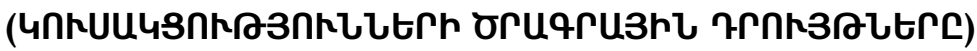

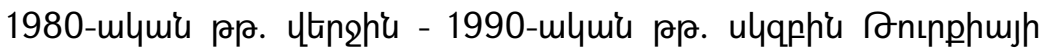

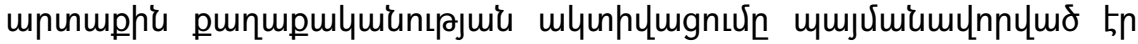

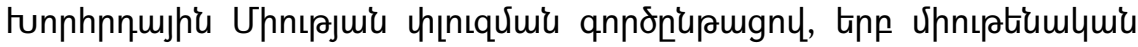

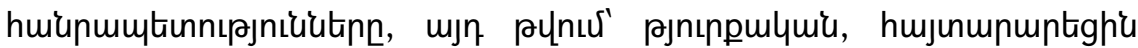

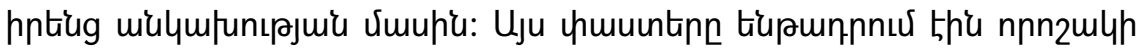

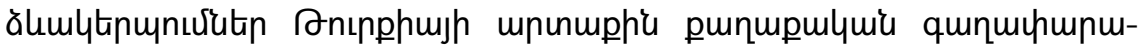

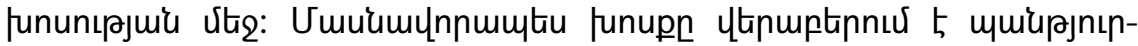

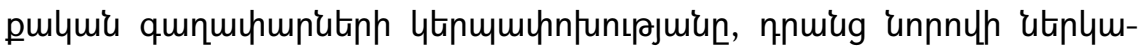

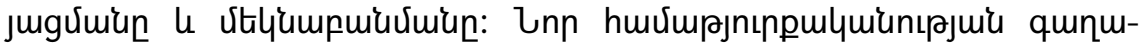

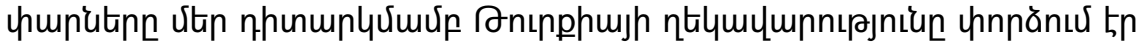

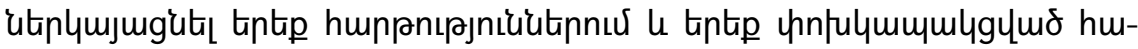
vimlumptinny.

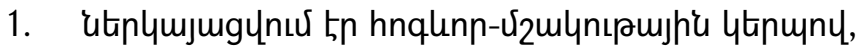

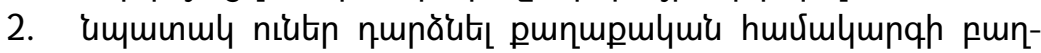
yugnighs vimu,

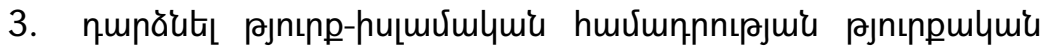
punumphsh hhúpn:

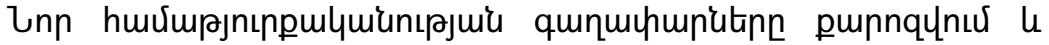

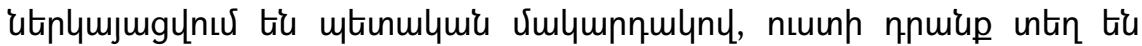

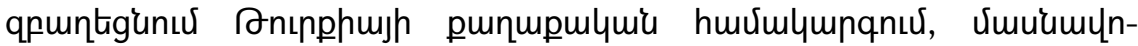

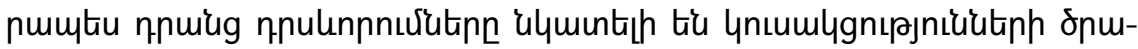

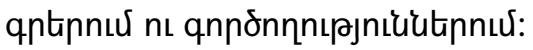

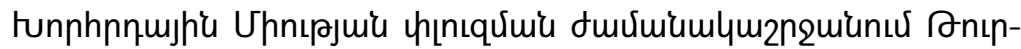

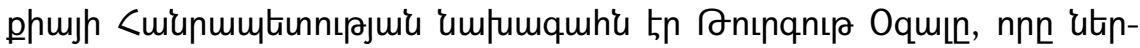
qujugunuर tn "Umjn hujntiuhp" 4nıumlygnıpjnıun (Anavatan Partisi):

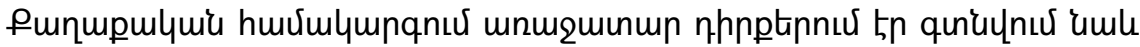

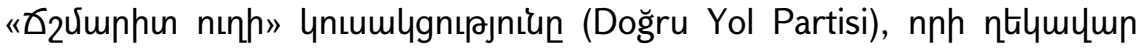

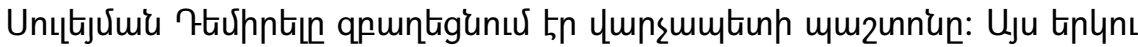




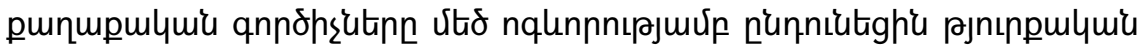

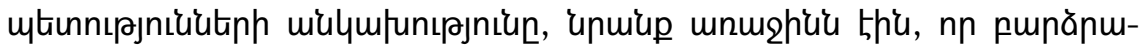

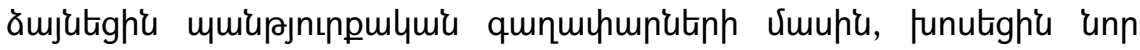

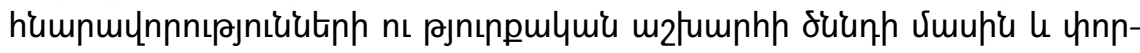

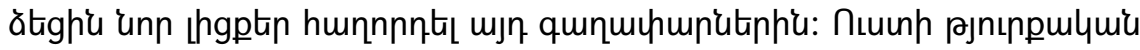

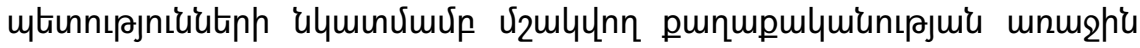

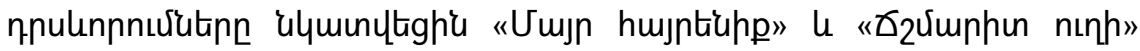

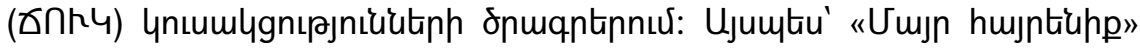

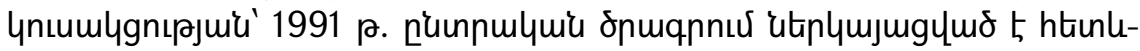

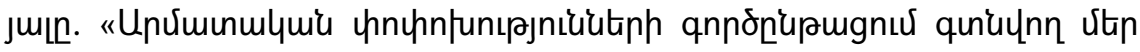

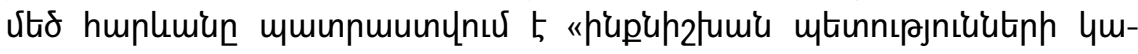

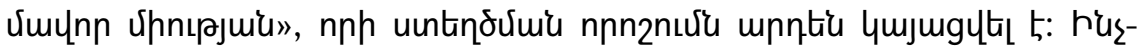

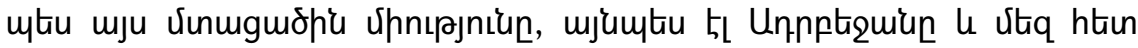

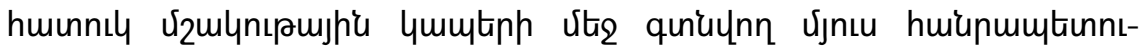

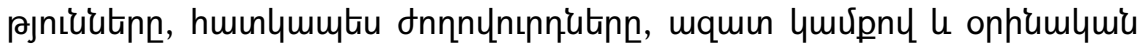

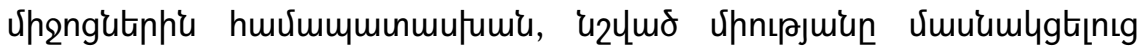

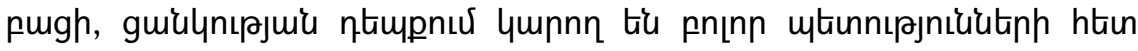

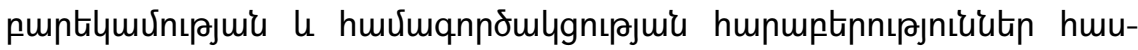

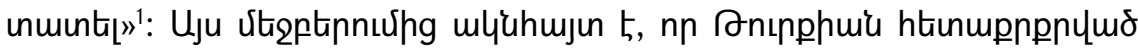

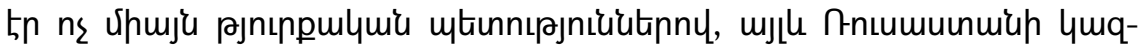

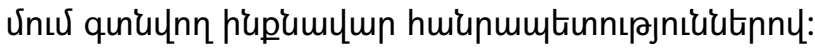

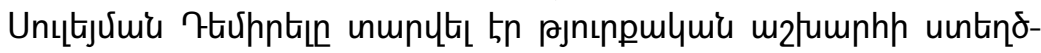

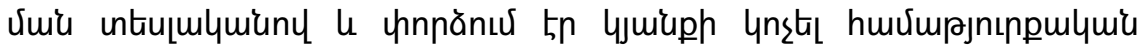

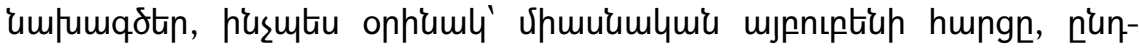

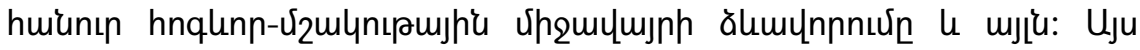

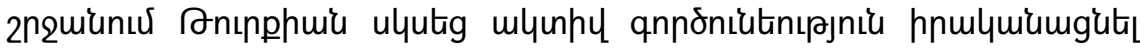

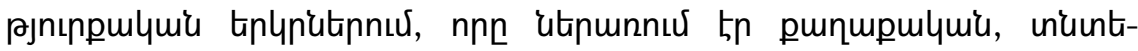

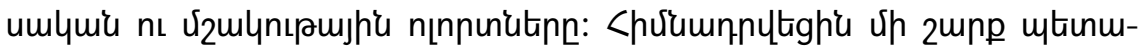

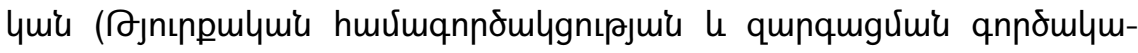

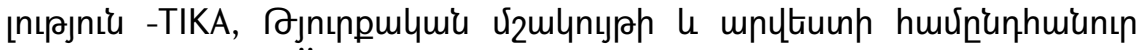

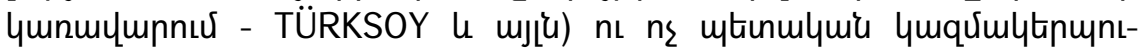

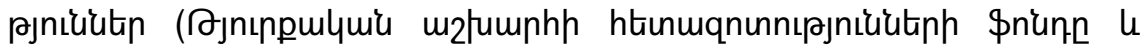

${ }^{1}$ Anavatan Partisi Seçim Beyannamesi, 20 Ekim 1991, s. 93-94. 


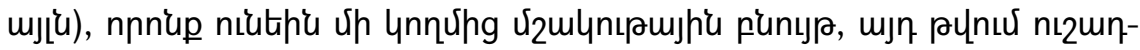

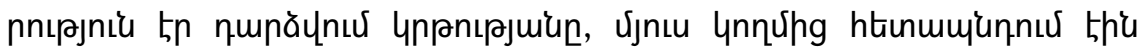

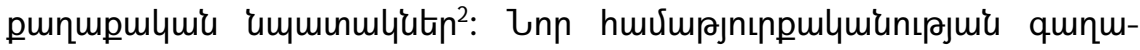

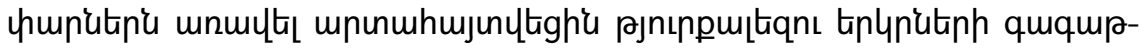

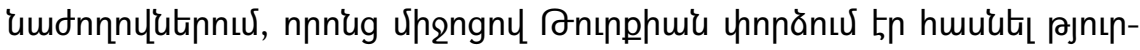

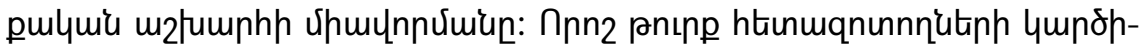

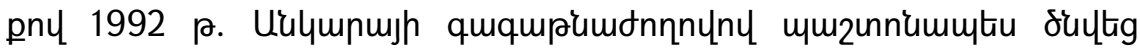

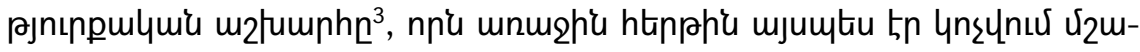

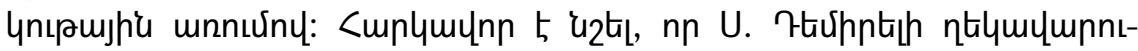

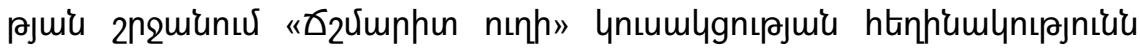

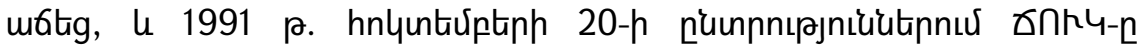

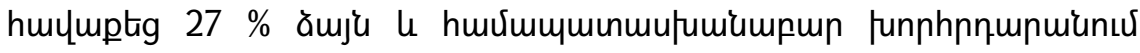

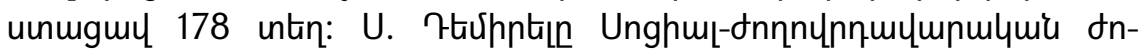

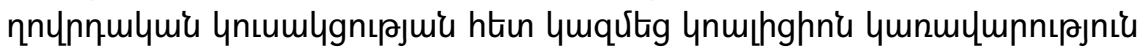

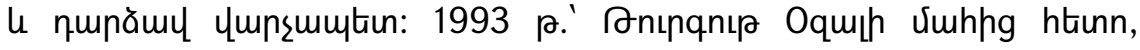

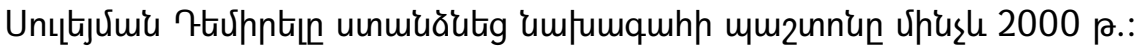

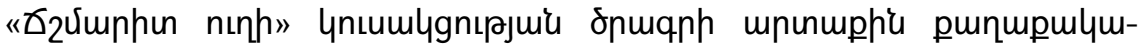

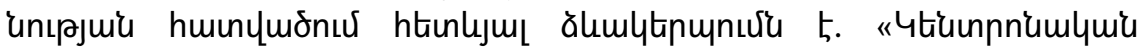

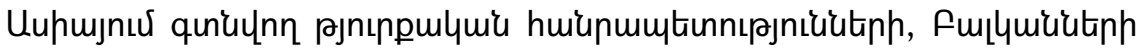

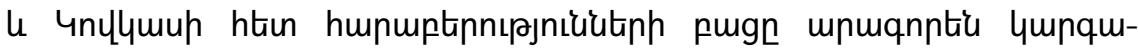

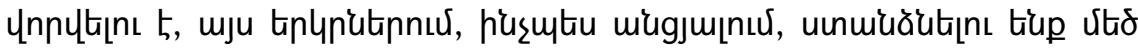

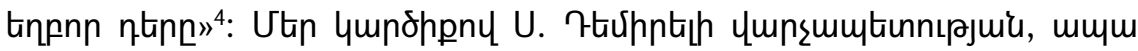

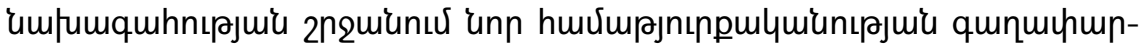

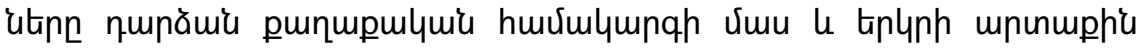

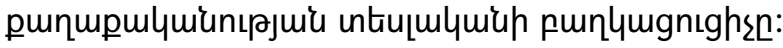

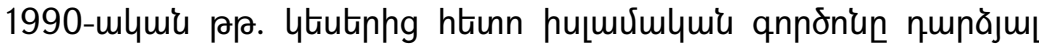

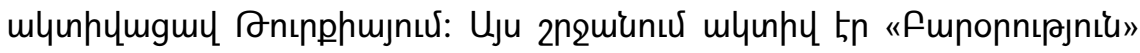

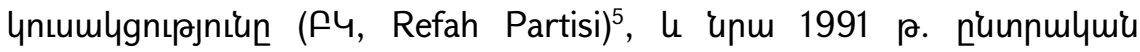

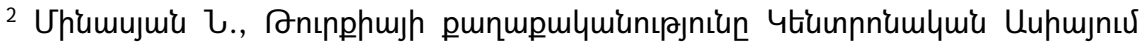
(1991-2007 рр.), tplumu, 2013, to 141-154:

${ }^{3}$ Bal Idris, Turkey's Relation with the West and Turkic Republics. Rise and Fall of the Turkish Model, England, 2000, p. 81.

${ }^{4}$ Doğru Yol Partisi, Parti Programi, http://www.dyp.com.tr/ (25.06.2017).

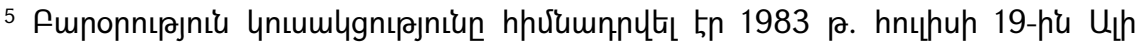
161 


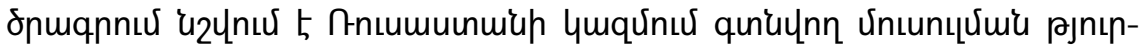

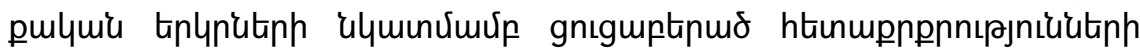

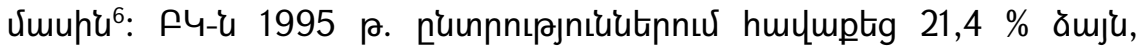

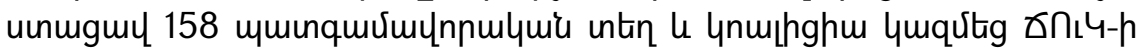

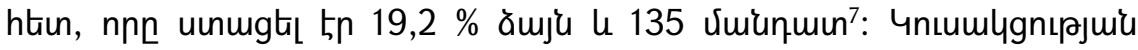

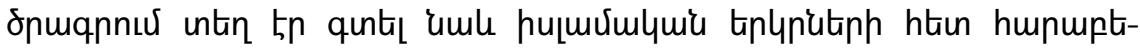

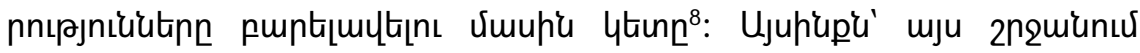

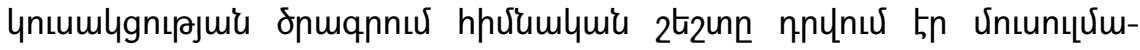

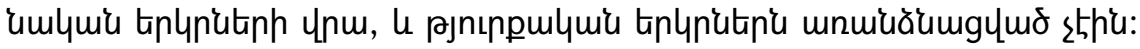

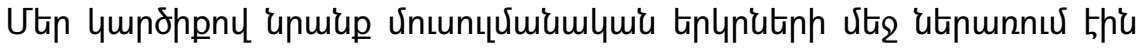

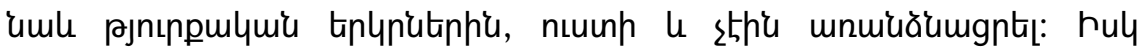

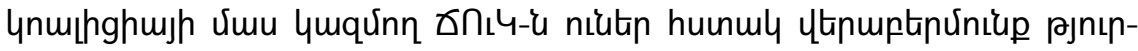

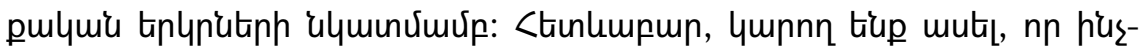

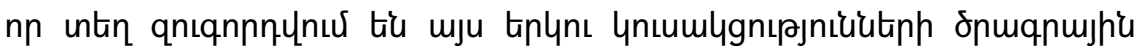

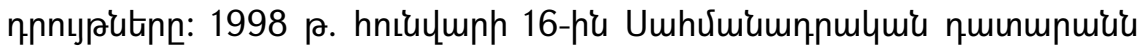

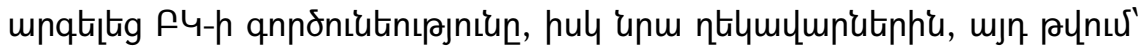

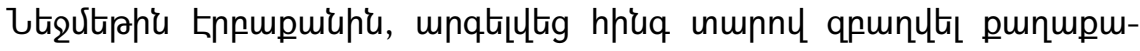

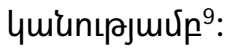

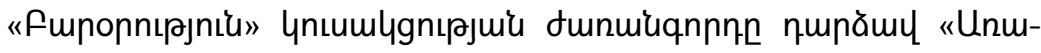
phunıpjniu»» unıumlgnıpjniun (U५, Fazilet Partisi): U५-h qunqugưưu

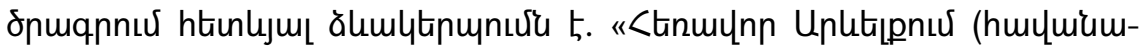

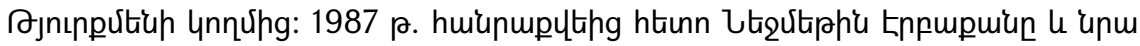

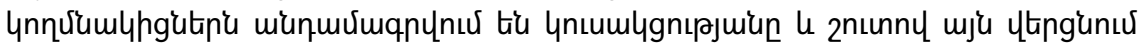
hntiug ythmuhulnnnnıpjuiu unuly: M. Hakan Yavuz, Political Islam and the Welfare (Refah) Party in Turkey, Comparative Politics, Vol. 30, No 1, October 1997, p. 72. ${ }^{6}$ Refah Partisi Seçim Beyannamesi, 20 Ekim 1991 Genel Seçimi, Ankara, 1991, s. 66.

7 1983-2007 Yillari Arasinda Yapilan Milletvekili Genel Seçimleri, Seçim Tarihi:

24.12.1995, http://www.ysk.gov.tr

${ }^{8}$ Refah Partisi böyle kapatildi, Yeni Akit, 17 Ocak 2016, http://www.yeniakit.com.tr/haber/refah-partisi-boyle-kapatildi-122558.html (29.06.2017).

${ }^{9}$ Milli Görüş'ten 4 parti kapatildi, Sabah, 15 Mart 2008, http://arsiv.sabah.com.tr/2008/03/15/haber,0E0014F9515341A98B5A573C4568C E0D.html (28.06.2017). 


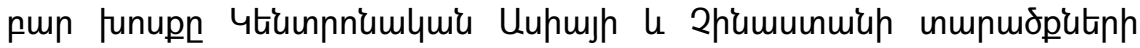

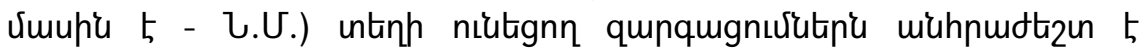

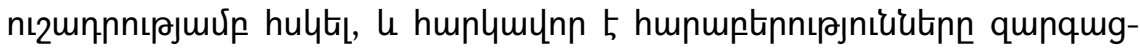

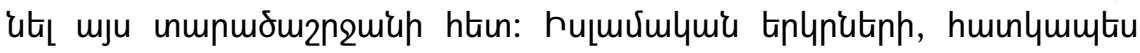

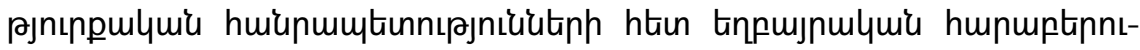

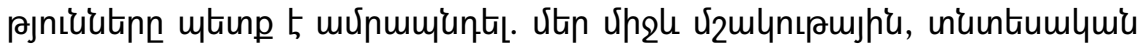

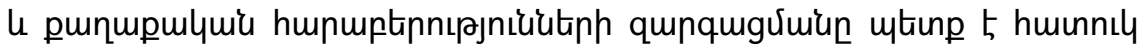

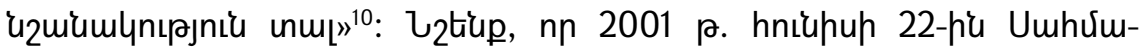

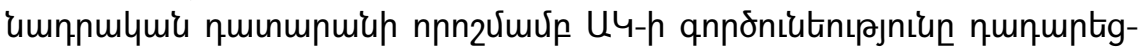
4tig ${ }^{11}:$

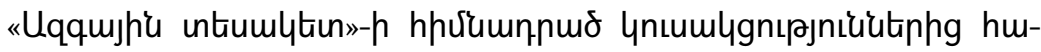

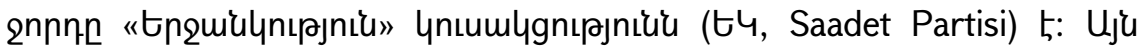

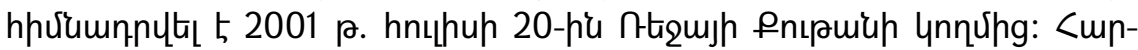

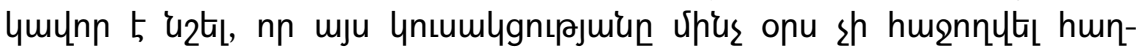

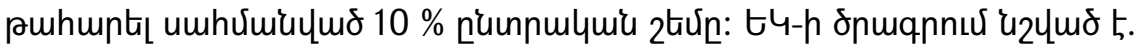

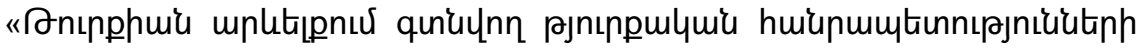

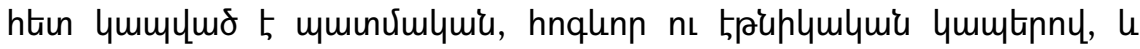

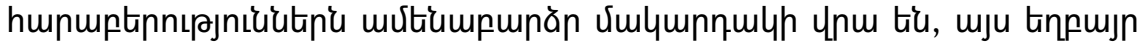

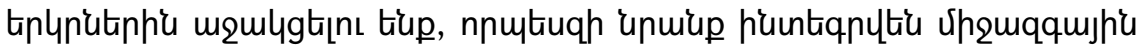

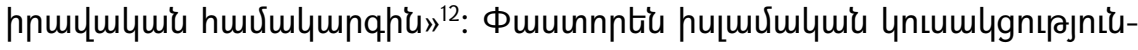

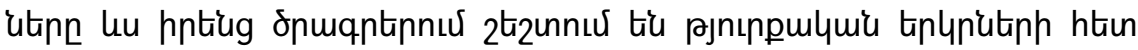

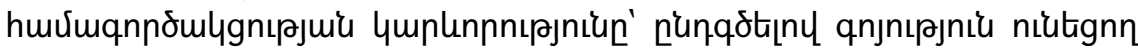

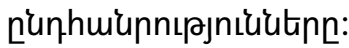

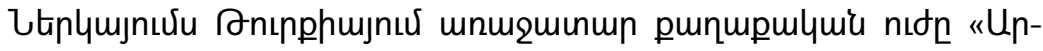

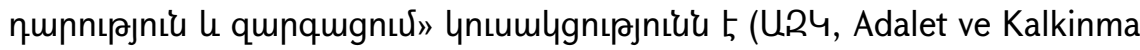

\footnotetext{
${ }^{10}$ Fazilet Partisi, "Öncü Türkiye için elele", Kalkinma Programi, Ankara, 1998, s. 35.

${ }^{11}$ Anayasa Mahkemesi'nin Kapatma Karari, 22 Haziran 2001 - 5 Ocak 2002, BELGEnet, http://web.archive.org/web/20120301235814/http://www.belgenet.com:80/arsiv/fazi let.html (30.06.2017). Umhưuiumnnulymí quinumuiuh nnn2nuर्u multh Uumunuuरuuu'u unt'u Anayasa Mahkemesi Karari, Resmi Gazete, 05 Ocak 2002, Sayi 24631 (Mükerrer), s. 173-197.

${ }^{12}$ Saadet Partisi Programi, 04.05. 2014, s. 28.
} 


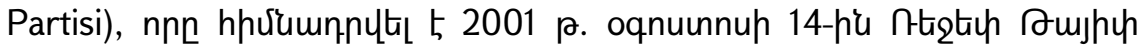

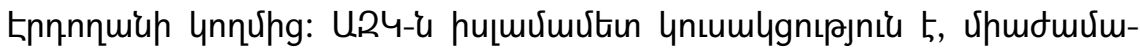

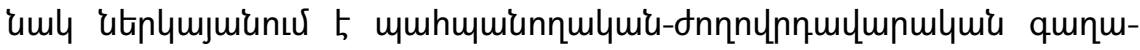

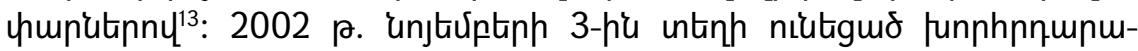

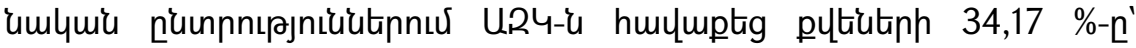

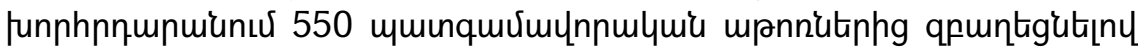

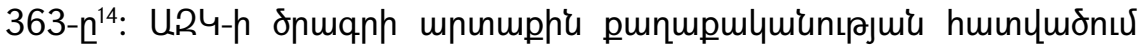

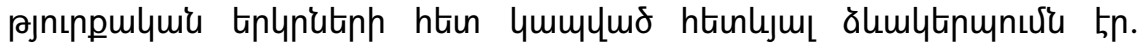

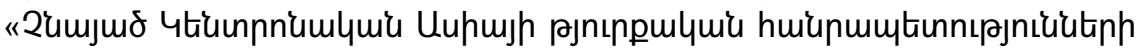

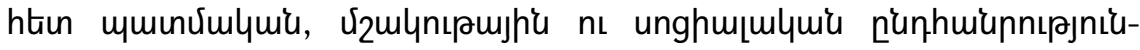

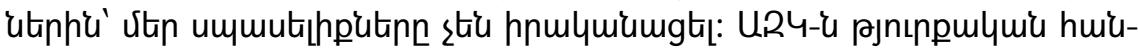

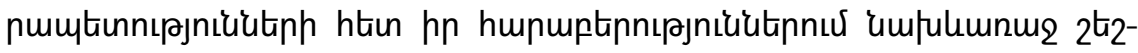

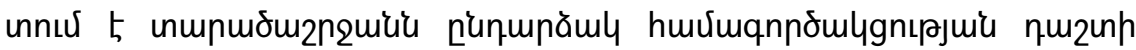

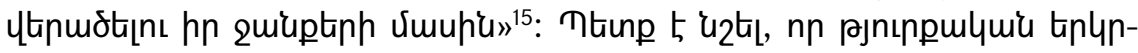

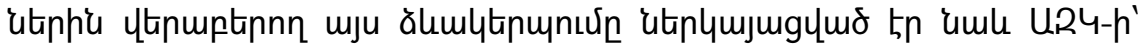

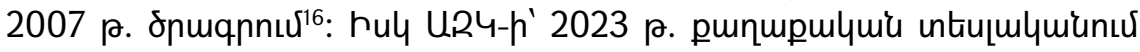

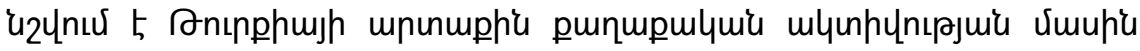

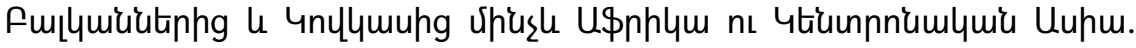

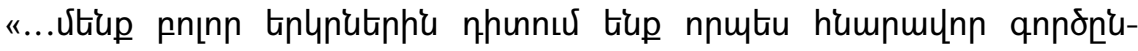

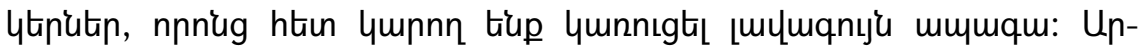

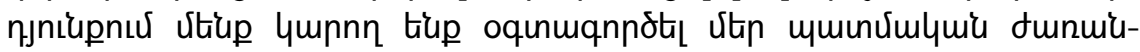

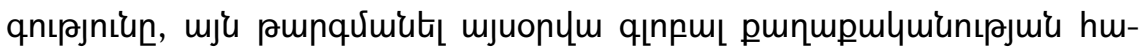

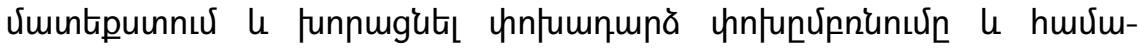

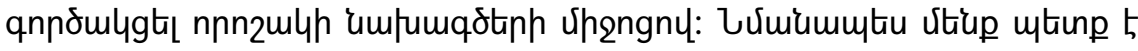

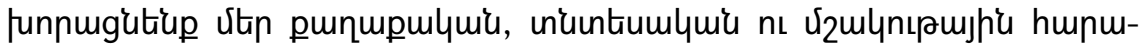

${ }^{13}$ Alev Çinar, The Justice and Development Party: Turkey's Experience with Islam, Democracy, Liberalism and Secularism, International Journal of Middle East Studies, Vol. 43, No 3, August 2011, pp. 531-532.

1403 Kasim 2002 XXII. Dönem Milletvekili Genel Seçimi, http://www.ysk.gov.tr/ysk/docs/2002MilletvekiliSecimi/turkiye/cevremilletvekilisayisi .pdf (20.10.2017)

${ }^{15}$ AK Parti Kalkinma ve Demokratikleşme Programi, Ankara, 2002, s. 108.

${ }^{16}$ AK Parti Programi, http://www.akparti.org.tr/site/akparti/parti-programi\#bolum (04.06.2017) 


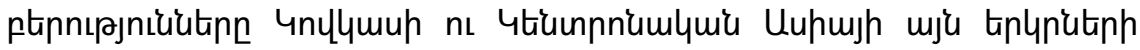

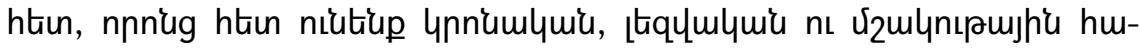

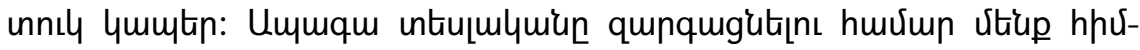

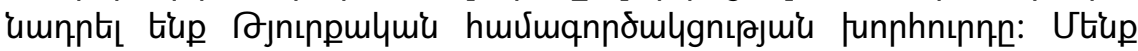

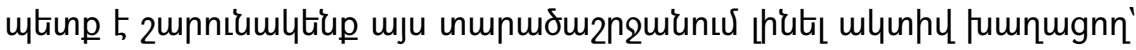

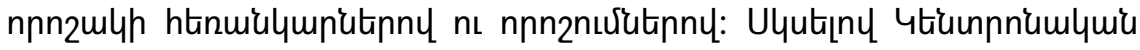

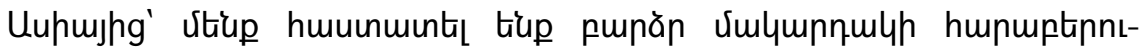

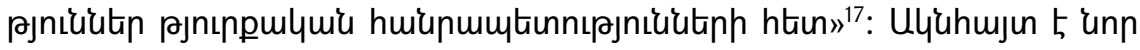

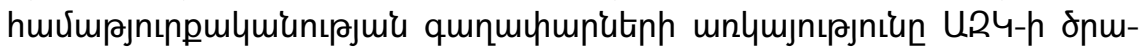

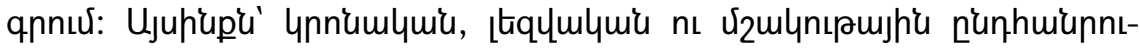

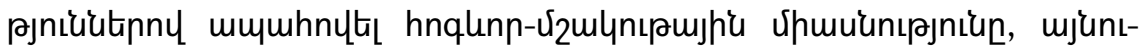

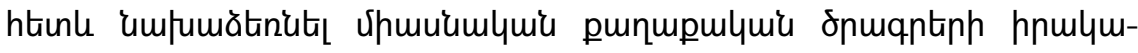

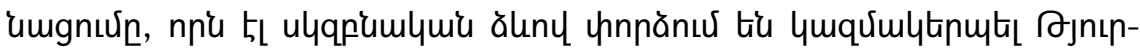

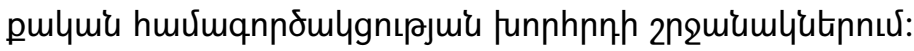

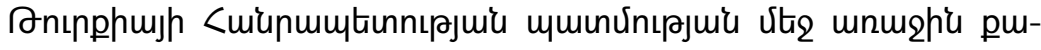

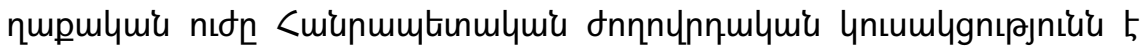

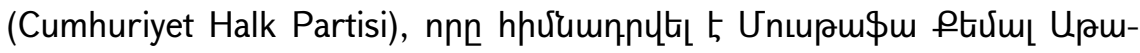

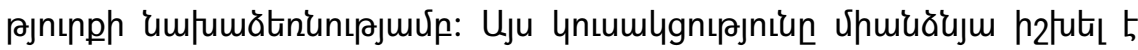

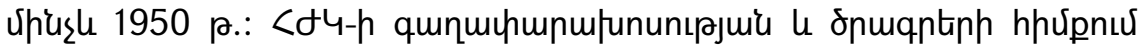

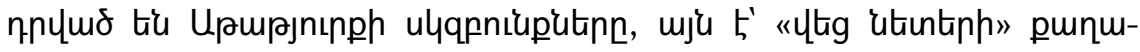

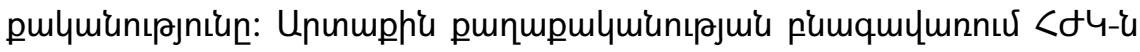

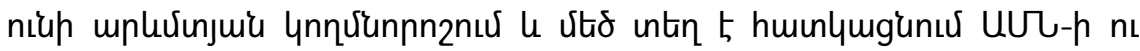

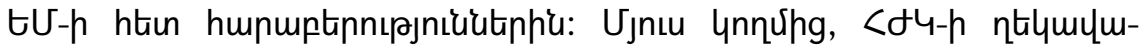

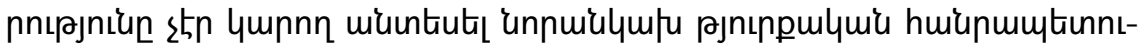

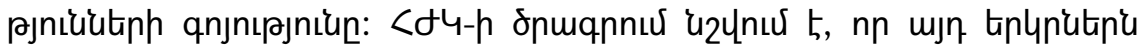

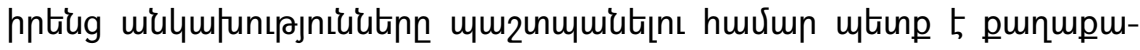

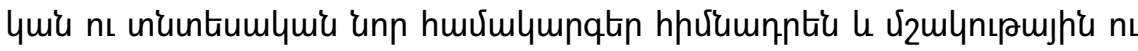

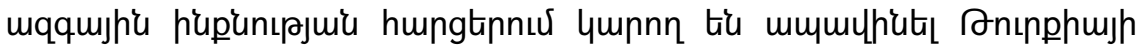

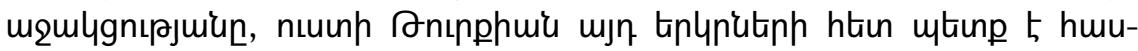

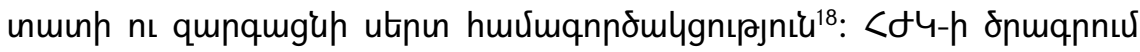

\footnotetext{
${ }^{17}$ Ak Partisi 2023 Siyasi Vizyonu, Siyaset, Toplum, Dunya, 2012, s. 63.

${ }^{18}$ Çağdaş Türkiye İçin Değişim, Cumhuriyet Halk Partisi Programi, Ankara, 2008, s. 130.
} 


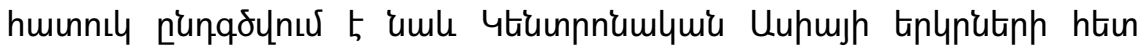

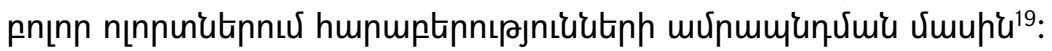

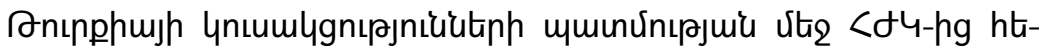

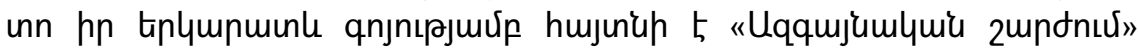

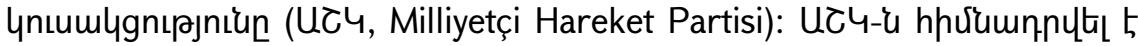

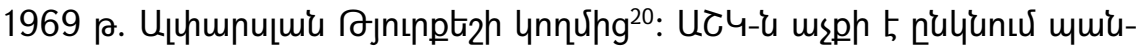

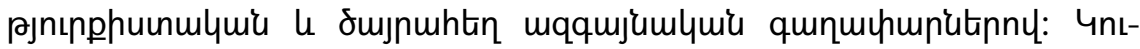

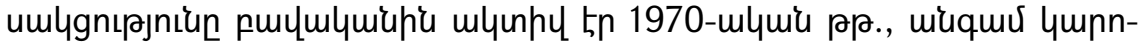

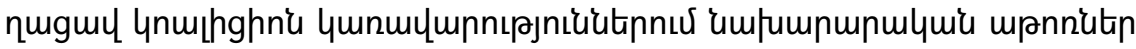

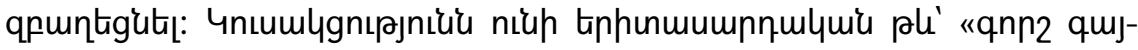

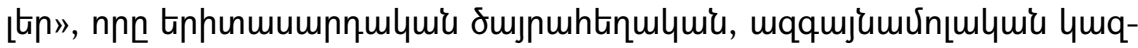

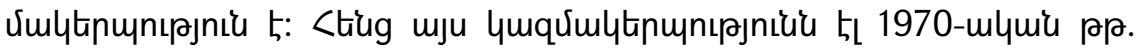

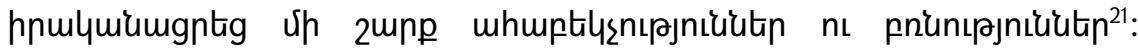

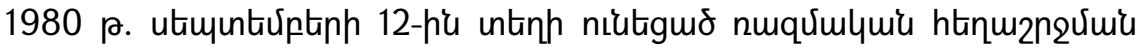

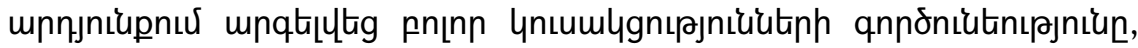

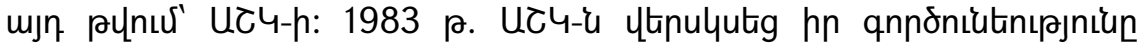

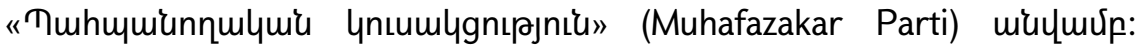

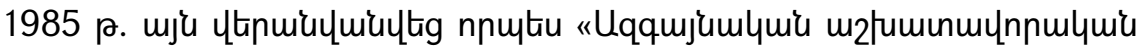

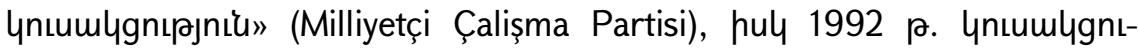

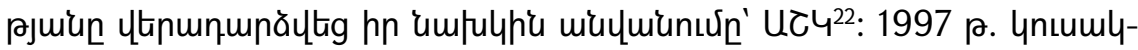

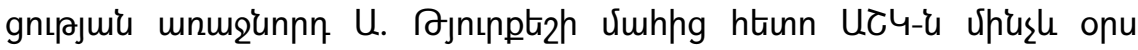

19 Unıృ untinnư, t2 128 :

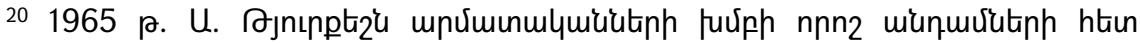

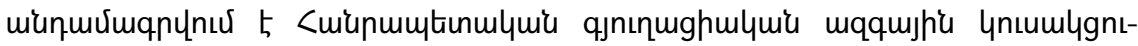

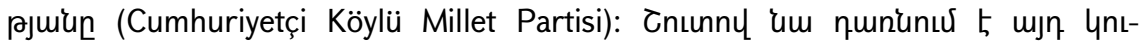

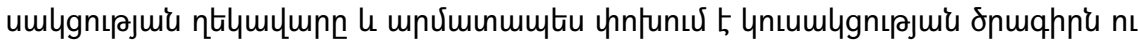

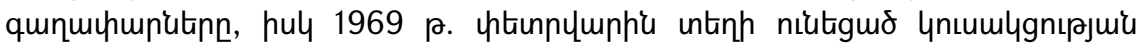

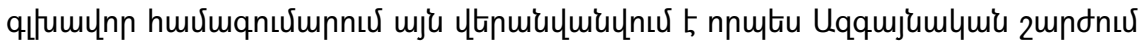
4nıumugnıpniu:

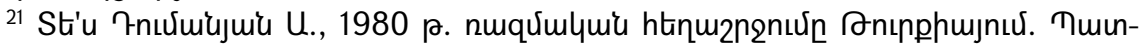
Gunutinn, nüumgne, htinlumiuputinn, tplumi, 2016, t2 68-80:

${ }^{22}$ Gökhan Karakurt, Siyasi Partilerin Doğuş Teorileri, Parti Tipolojileri ve Kurumsallaşmalari Bağlaminda Milliyetçi Hareket Partisi Üzerine Bir Değerlendirme, Uluslararasi Politik Araştirmalar Dergisi, Yil: 2, Cilt: 2, Sayi: 1, 2016, s. 43. 


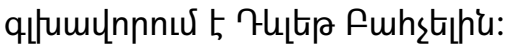

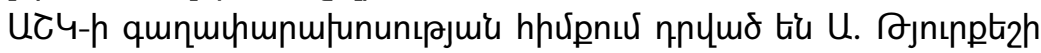

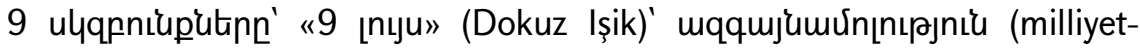

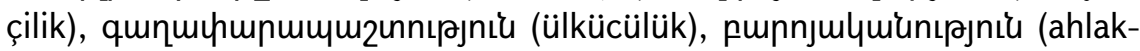

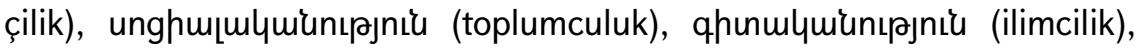

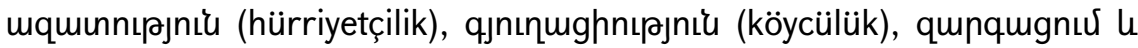

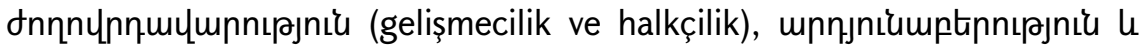

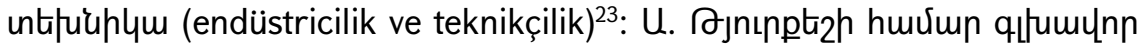

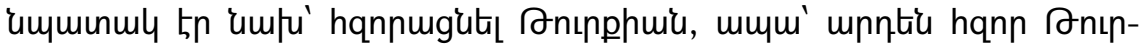

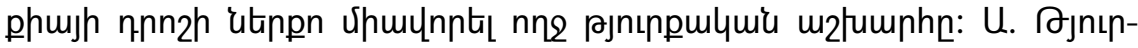

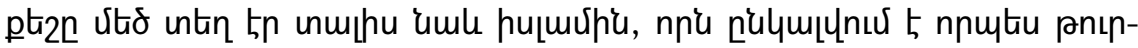

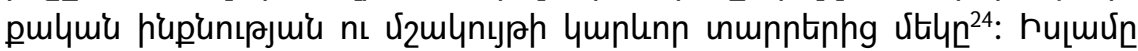

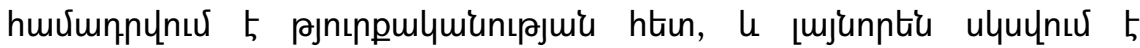

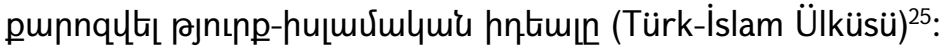

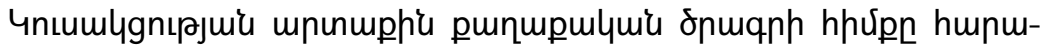

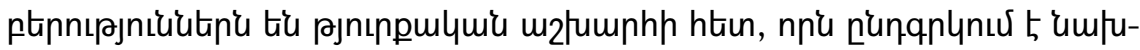

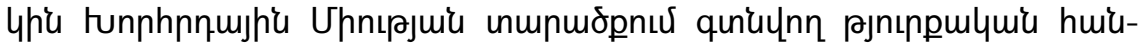

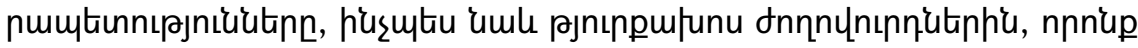

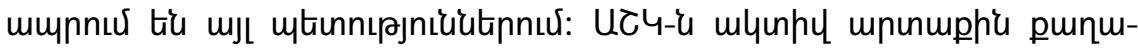

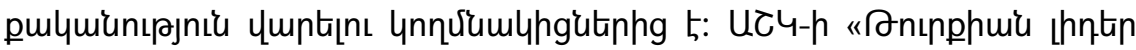

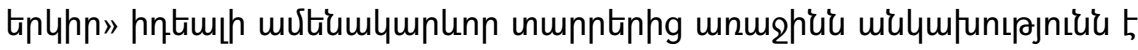

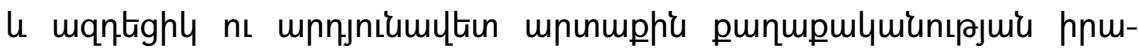

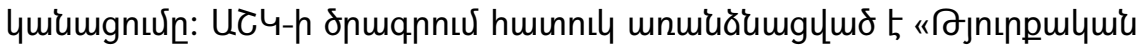

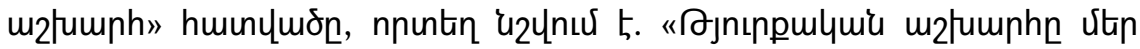

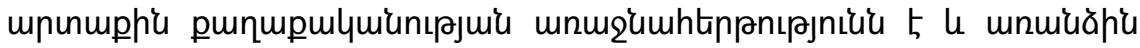

\footnotetext{
23 Türkeş A., Milli Doktrin Dokuz Işik, İstanbul, 2010, s. 20-24.

${ }^{24}$ E. Burak Arikan, The Programme of National Action Party: An Iron Hand in a Velvet Clove?, Middle Eastern Studies, Vol. 34, No, 4, October 1998, p. 123.

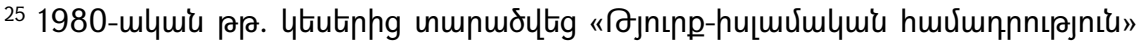

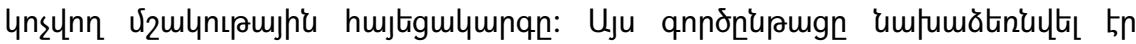

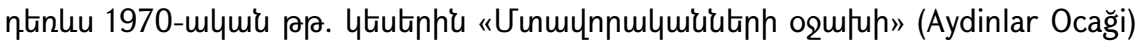

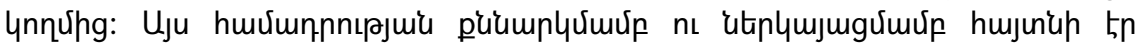

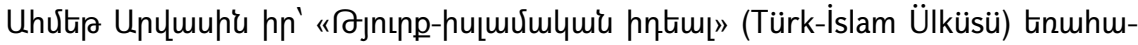
unn m2fumunnıرuuर्up:
} 


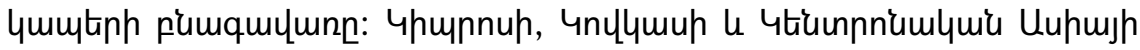

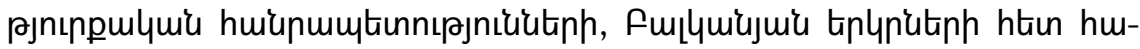

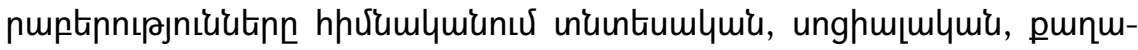

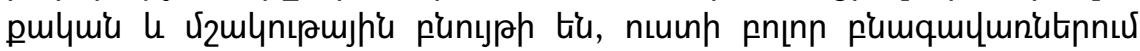

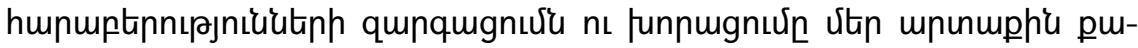

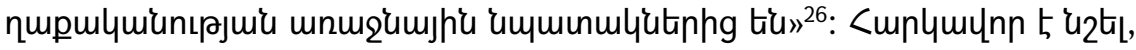

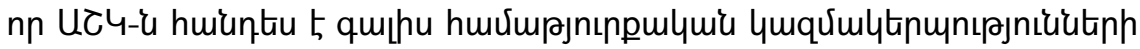

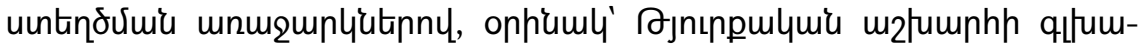

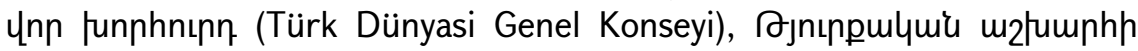
5ütinqtinnly funnhnınп (Türk Dünyasi Enerji Konseyi), Dرnınpulquiu

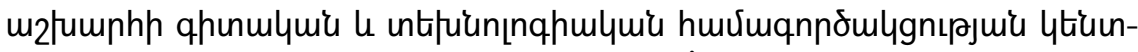
nnú (Türk Dünyasi Bilimsel ve Teknolojik İşbirliği Merkezi): hul 9nn2

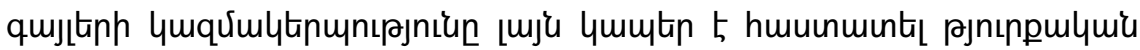

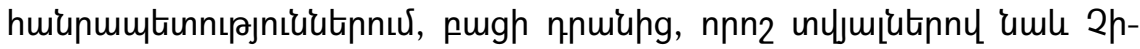

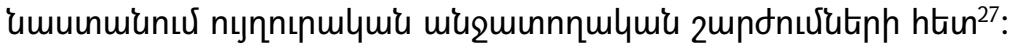

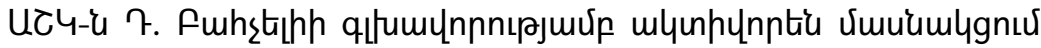

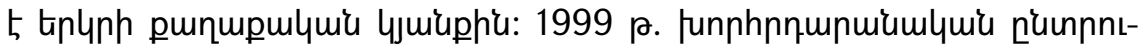

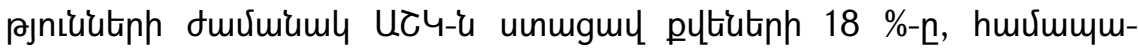

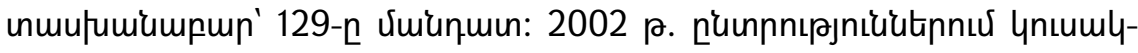

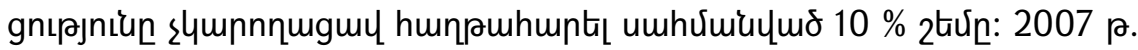

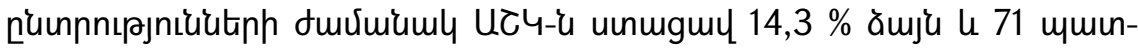

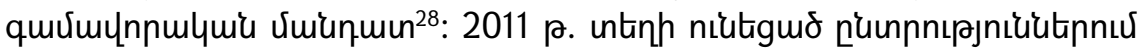

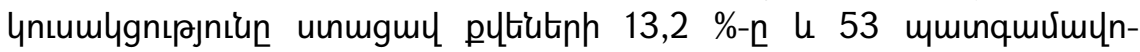

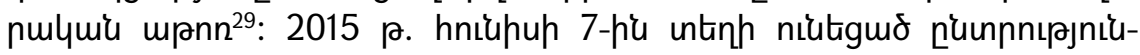

\footnotetext{
${ }^{26}$ Milliyetçi Hareket Partisi, Parti Programi, “Geleceğe Doğru”, Ankara, 8 Kasim 2009, s. 126-127.

${ }^{27}$ Bhavna Singh, Separatism in Xinjiang: Between Local Problems and International Jihad www.ipcs.org/pdf file/issue/SR122-CRP-

SeparatisminXinjiang.pdf (18.10.2017).

28 1983-2007 Yillari Arasinda Yapilan Milletvekili Genel Seçimleri, http://www.ysk.gov.tr

2912 Haziran 2011. XXIV. Dönem Milletvekili Genel Seçimi, http://www.ysk.gov.tr/ysk/docs/2011MilletvekiliSecimi/gumrukharic/gumrukharic.pd $\underline{f}(19.10 .2017)$.
} 


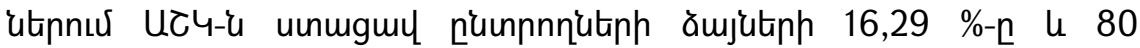

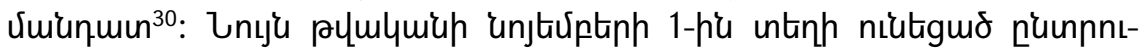

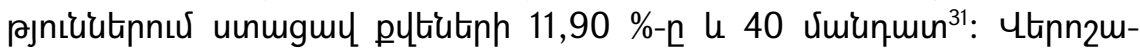

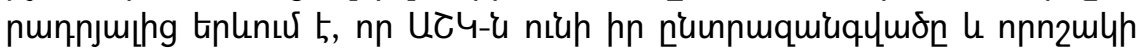

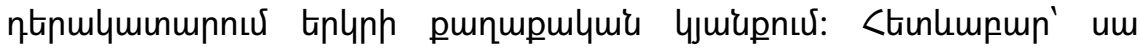

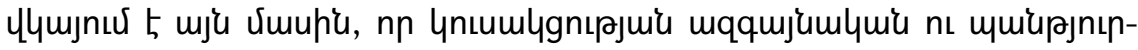

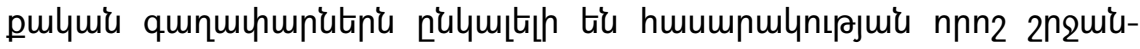
utiph huvium:

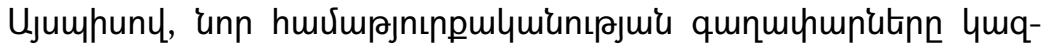

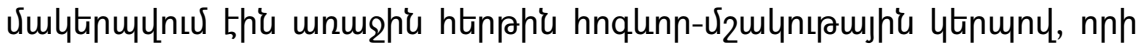

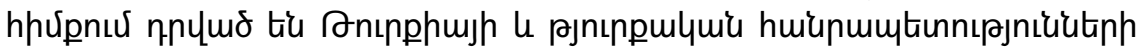

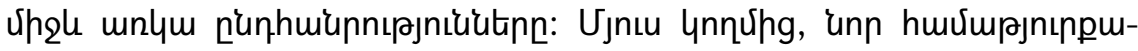

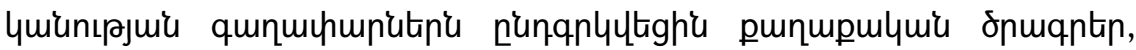

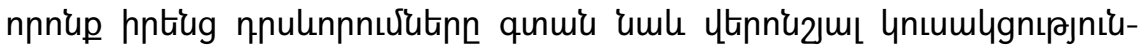

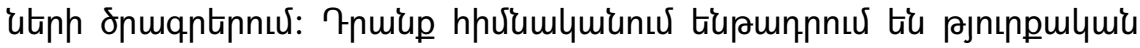

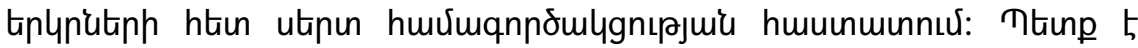

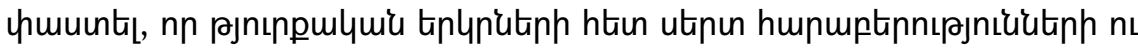

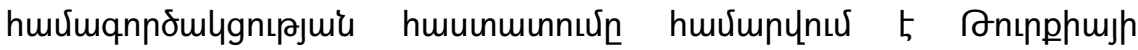

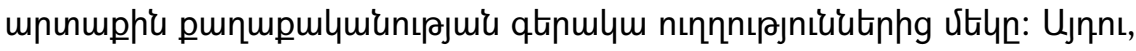

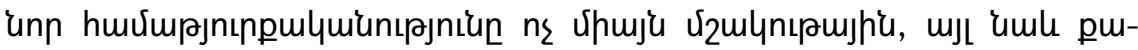

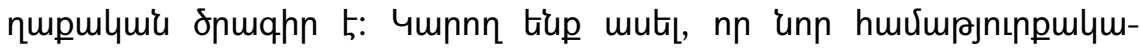

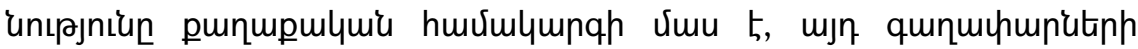

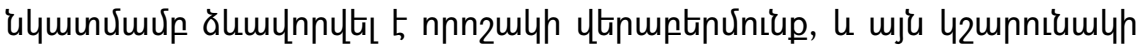

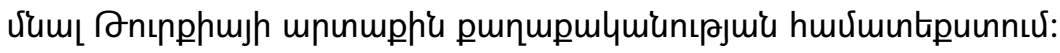

307 Haziran 2015. 25. Dönem Milletvekili Genel Seçimi, http://www.ysk.gov.tr/ysk/content/conn/YSKUCM/path/Contribution\%20Folders/Hab erDosya/2015-MV_dagilimlari.pdf (18.10.2017).

311 Kasim 2015. 26. Dönem Milletvekili Genel Seçimi, http://www.ysk.gov.tr/ysk/content/conn/YSKUCM/path/Contribution\%20Folders/Hab erDosya/2015MVES-PartiYasDagilimi-Grafik.pdf (20.10.2017). 


\title{
THE NEO PAN-TURKISM IDEAS IN THE POLITICAL SYSTEM OF TURKEY (THE PROGRAM THESES OF PARTIES)
}

\begin{abstract}
At the beginning of 1990s Turkey's foreign policy activity was connected with the collapse of the Soviet Union and the independence of the Turkic republics. The Pan-Turkism ideas were transformed during this period and they were introduced in a new way. The neo Pan-Turkism ideas were presented by three interconnected systems: the first as a spiritual cultural program, the second as a part of the political system, the third as Turkic component of the Turkic-Islamic synthesis. All Turkish parties attach great importance to the cooperation with Turkic republics in their programs. This especially emphasizes the ruling Justice and Development Party. The Nationalist Action Party is well known for PanTurkism and nationalist ideas. The NAP suggests to establish Pan-Turkic organizations. Neo Pan-Turkism is not only a cultural project, it is also a political program. We can say that the Neo Pan-Turkism is a part of the political system and it will stay in the context of Turkey's foreign policy.
\end{abstract}

